\title{
The road to sustainable transportation
}

\author{
Jo HERMAns
}

Leiden University - P.O. Box 9504, 2300 RA Leiden, The Netherlands

Summary. - Since most modes of transportation rely on liquid energy carriers like gasoline or diesel, the approaching end of the fossil fuel era poses a special challenge. One should bear in mind that nothing matches the energy density of liquid fuels. It is, therefore, important to consider the efficiency of various modes of transportation and explore alternative options for energy carriers. This includes a feasibility study of the use of solar energy in transportation. In this perspective various modes of transportation are briefly reviewed and the possible alternative energy carriers assessed.

\section{1. - Physics of transportation}

In order to obtain insight into the possibilities of improving the performance of transport, it is useful to first turn to the fundamental physics of transportation. The key here is the resistance suffered by any vehicle moving at a certain speed, because the resistance directly determines the energy use per unit distance. In other words: the resistance in newtons equals the energy use in $\mathrm{J} / \mathrm{m}$, or - expressed more conveniently — in $\mathrm{kJ} / \mathrm{km}$.

For vehicles on wheels the resistance has two components: rolling resistance $F_{\mathrm{r}}$ and air resistance or aerodynamic drag $F_{\mathrm{d}}$. For the latter contribution one should bear in 
TABLE I. - Typical values of the aerodynamic drag coefficient $C_{\mathrm{d}}$ (source for specified cars brands: https://en.wikipedia.org/wiki/Automobile_drag_coefficient).

\begin{tabular}{ll}
\hline Flat surface & $C_{\mathrm{d}} \approx 1$ \\
Citroen 2CV & 0.51 \\
Clumsy 1960s car & 0.4 \\
Citroen C4 & 0.28 \\
Toyota Prius & 0.25 \\
Tesla model S & 0.24 \\
Nuna solar car, World Solar Challenge winner & 0.07 \\
Ideal streamline & 0.05 \\
\hline
\end{tabular}

mind that the flow is not laminar but turbulent. So the total resistance can be written as

$$
F=F_{\mathrm{r}}+F_{\mathrm{d}}=C_{\mathrm{r}} \times m g+C_{\mathrm{d}} \times A \times(1 / 2) \rho v^{2},
$$

where $C_{\mathrm{r}}$ is the rolling resistance coefficient, $m$ is the mass, $g$ the acceleration of gravity, $C_{\mathrm{d}}$ the drag coefficient, $A$ the frontal area, $\rho$ the air density and $v$ the speed. Note that $F_{\mathrm{r}}$ is independent of speed while $F_{\mathrm{d}}$ is proportional to the speed squared (cf. Bernoulli's law). For an average car the rolling resistance dominates at speeds up to about $60 \mathrm{~km} / \mathrm{h}$, and the drag becomes dominant at higher speed.

The rolling resistance for tires is caused by the fact that the forces related to compression and expansion of rubber are not equal: there is some hysteresis. Note that the value of $C_{\mathrm{r}}$ must be on the order of 0.01 , since a slope of approximately $1 \%$ suffices to get a car rolling. Extensive measurements [1] have shown that values of $C_{\mathrm{r}}$ vary from 0.007 to 0.014 . Note also that $F_{\mathrm{r}}$ is proportional to the mass of the vehicle. Therefore, in urban traffic the mass is a major factor in energy use, the more so since the energy lost in the braking/accelerating cycles is also proportional to the mass.

The drag coefficient $C_{\mathrm{d}}$ depends totally on the shape of the vehicle. Bernoulli's law tells us that it must be around unity for a flat plate whose surface is perpendicular to the direction of motion. A number of values are given in table I.

1'1. Cars. - At speeds around $100 \mathrm{~km} / \mathrm{h}$ it is found that the total resistance of an average car is around $500 \mathrm{~N}$. So the mechanical energy use of a car on the highway is around $500 \mathrm{~kJ} / \mathrm{km}$. With an efficiency of $25 \%$ this means that the primary energy use (gasoline, for example) is around $2 \mathrm{MJ} / \mathrm{km}$. Given an energy of combustion of $35 \mathrm{MJ} /$ litre, we see that the energy use for driving on the highway can be expected to be around $18 \mathrm{~km} / \mathrm{L}$, which corresponds nicely to the real-life value.

The power needed for driving on the highway is found by multiplying the total resistance $(500 \mathrm{~N})$ by the speed (around $30 \mathrm{~m} / \mathrm{s}$ ), which yields approximately $15 \mathrm{~kW}$. 
1`2. Buses, trains, aircraft. - If the energy use for cars, buses and trains are compared, the following picture emerges. It is found $[2,3]$ that, per seat, buses are comparable to cars in city traffic, but more efficient in long-distance travel by a factor of 2 to 3 . Trains can beat cars by a factor of 10 per seat, provided they do not stop frequently. An exception is the TGV (or high-speed train) whose energy use per seat is comparable to a car.

Aircraft form a special case since they have no rolling resistance once they are airborne. They are found to have a fuel consumption per seat which is about twice as large as for cars. Here, the disadvantage of very high speed is offset largely by the fact that the air density at cruising altitude is only one fourth of the density at sea level, combined with a low value of $C_{\mathrm{d}}$ and a relatively small frontal area per seat. An interesting feature for air travel is that long-haul flights carry a surprising amount of fuel. The mass of the fuel at take-off can be roughly equal to the mass of the empty plane. Put differently, it amounts to a fuel mass of 250 to $300 \mathrm{~kg}$ per passenger.

\section{2. - Future energy carriers and sources}

Transportation requires a convenient mobile energy carrier. For most applications liquid fuels like gasoline, diesel or kerosene are exceptionally well suited, since their energy density is second to none. The question is which energy carriers will be most suited to replace oil-based fuels after the fossil-fuel era. The most obvious options seem to be biofuels, batteries (in combination with supercapacitors), hydrogen and metal fuels. But also solar power must be considered.

2'1. Biofuels. - This does not seem a viable option, for several reasons. First, the efficiency of photosynthesis is rather poor: around 0.5 to $1 \%$ in moderate-climate regions, like in Germany for example, up to about 3\% in favorable climates. This means that "first generation biofuels", which are derived from food products like corn, sugar or palm oil, are in competition with the world food supply ("food for the poor vs. fuel for the rich"). Second, if the losses in conversion and changes in land use are also considered, it is found that the $\mathrm{CO}_{2}$ emission of biofuel-powered transport is at present comparable to that of fossil fuels, or even larger for "first generation biofuels" $[4,5]$.

2.2. Batteries and supercapacitors. - Electric vehicles (EVs) have many advantages over vehicles powered by an internal-combustion engine. Electric motors are light and relatively simple, and they do not have to idle when the vehicle is not moving. Moreover they deliver maximum torque immediately, and it is easy to save energy by regenerative braking.

One should distinguish hybrid cars, which ultimately run on gasoline or diesel; plugin hybrids, which run partially on electricity; and real electric vehicles (EVs) which run exclusively on electricity. We will consider EVs in this chapter.

There is little doubt that electric vehicles will be the leading kind of car in the distant future. In the present transition period, however, the advantages of electric cars are marginal. The $\mathrm{CO}_{2}$ emission, for example, may not be lower than for a car powered 
TABLE II. - The energy density of various media for storing electricity. For comparison: the energy density of gasoline is about $40 \mathrm{MJ} / \mathrm{kg}$ or $11 \mathrm{kWh} / \mathrm{kg}$ in terms of thermal energy.

\begin{tabular}{ll}
\hline Lead battery & $\approx 0.03 \mathrm{kWh} / \mathrm{kg}$ \\
Ni-MH battery & $\approx 0.08 \mathrm{kWh} / \mathrm{kg}$ \\
Li-ion polymer battery $(\mathrm{LiPo})$ & $\approx 0.20 \mathrm{kWh} / \mathrm{kg}$ \\
Li-ion battery & $\approx 0.25 \mathrm{kWh} / \mathrm{kg}$ \\
Supercapacitor & $\approx 0.005 \mathrm{kWh} / \mathrm{kg}$ \\
& $\approx 0.02 \mathrm{kWh} / \mathrm{kg}$ \\
\hline
\end{tabular}

by diesel or gasoline, depending on the way the electricity is generated. Let us take an $\mathrm{EV}$ using electricity generated in a coal-fired power plant. The $\mathrm{CO}_{2}$ emission of coal combustion per unit of energy is $89 \mathrm{~kg} \mathrm{CO} /$ GJ. If we take the net efficiency of the power plant in producing electricity to be $35 \%$ and consider some additional losses in the charge-discharge cycles of the battery plus a few percent in the electric motor, the final fuel-to-wheel efficiency can be estimated to be $30 \%$. This means that the above $\mathrm{CO}_{2}$ emission must be raised to $89 / 0.30 \mathrm{~kg} \mathrm{CO} / \mathrm{GJ}=297 \mathrm{CO}_{2} / \mathrm{GJ}$. The emission of a diesel-powered car having an efficiency of $25 \%$ compares favorably with this value: taking the specific emission of oil as $71 \mathrm{~kg} \mathrm{CO} / \mathrm{GJ}$, we end up with an emission of $71 / 0.25 \mathrm{~kg}$ $\mathrm{CO}_{2} / \mathrm{GJ}=284 \mathrm{~kg} \mathrm{CO} / \mathrm{GJ}$, which is even a bit less than it is for the electric car. An advantage of the $\mathrm{EV}$ is, of course, that the emission is at the power plant site rather than in urban areas.

Battery performance has been improving remarkably over the last years. The present (2016) energy density of Li-ion batteries is $0.25 \mathrm{kWh} / \mathrm{kg}$ [6]. This is much higher than, for example, traditional lead batteries, which have about $0.03 \mathrm{kWh} / \mathrm{kg}$ (see table II).

Even so, we should bear in mind that the energy density of batteries is still very low if compared to liquid fuels. One way to see this is to realize that a battery stack of $10 \mathrm{~kg}$ of Li-ion batteries contains the same amount of energy as a beer glass full of gasoline, the combustion energy of gasoline being about $36 \mathrm{~kJ} / \mathrm{L}$, or $10 \mathrm{kWh} / \mathrm{L}$. The advantage of a battery, of course, is that the energy it contains can be converted into mechanical energy without any losses in principle, and with losses of only a few percent in practice. By contrast, the efficiency of an internal combustion engine powered by gasoline is only about $20-25 \%$.

The price of Li-ion batteries at present (2016) is down to approximately 500 USD/ $\mathrm{kWh}[6]$.

Whereas batteries are well suited for storing energy, their performance in producing high power is limited. Therefore, batteries are most often accompanied by super capacitors (or "ultracapacitors" or "double layer capacitors"), because these can produce high power, being well suited for frequent charge and discharge cycles at high current and short duration. This is obviously important for regenerative breaking and rapid acceleration. One should realize that such capacitors have capacitances on the order of farads, or even kilofarads. This is many orders of magnitude larger than the traditional capacitors 
TABLE III. - Two Electric Vehicle types compared: EV1, a relatively light car having a small maximum range, and $E V 2$, a heavy car having a large maximum range.

\begin{tabular}{lll}
\hline & EV1 & EV2 \\
Mass & $1195 \mathrm{~kg}$ & $2085 \mathrm{~kg}$ \\
Electric motor max. power & $125 \mathrm{~kW}$ & $568 \mathrm{~kW}$ \\
Battery (Li-ion) & $19 \mathrm{kWh}$ & $85 \mathrm{kWh}$ \\
Energy use per $100 \mathrm{~km}$ & $14-17 \mathrm{kWh}$ & $24 \mathrm{kWh}$ \\
Maximum range & $130-160 \mathrm{~km}$ & $426 \mathrm{~km}(\mathrm{EPA})$ \\
\hline
\end{tabular}

in electronic devices, which have capacitances on the order of picofarads or microfarads. Supercapacitors can store typically $5 \mathrm{Wh} / \mathrm{kg}$, which is poor compared to $250 \mathrm{Wh} / \mathrm{kg}$ for Li-ion batteries, but they can deliver much higher powers: up to or exceeding $10 \mathrm{~kW} / \mathrm{kg}$. An interesting comparison between batteries and capacitors was given in Physics Today, December 2008 [7].

Given the limited energy density of batteries in terms of the number of GJ per kg, the maximum range of an $\mathrm{EV}$ is still an issue. In this context one may choose between two concepts: either opt for a relatively light EV having a small range and suited for example for commuter traffic, or a relatively heavy car having a large range. In table III two such cars are compared: EV1 (a BMW i3) and EV2 (a Tesla model S).

It is seen from table III that a large range comes at a price: EV2 has almost double the mass compared to EV1, and accordingly its energy use is higher. This illustrates that contemporary EVs should be chosen according to the prospective use regarding desired range and charge opportunities.

A drawback of EVs at present is the long charging time. This is easy to understand if we realize that the power for driving is around $15 \mathrm{~kW}$ (see sect. $1^{`} 1$ ). By comparison, the maximum power for a standard electrical outlet in a European home is limited to about $3.5 \mathrm{~kW}$ given a voltage of $230 \mathrm{~V}$ and a $16 \mathrm{~A}$ fuse. This means that for every hour driving on the highway we need a charging time of four hours, if we assume charging from a standard home outlet. It is illustrative to compare this with refueling gasoline. This is done at a rate of about 0.6 Liter per second. This corresponds to about $20 \mathrm{MJ} / \mathrm{s}$ or $20 \mathrm{MW}$ ! Another drawback of EVs in winter time is that heating the car is electric, so it goes at the expense of battery charge. For a car having an internal combustion engine heating is free, since it is simply extracted from the waste heat.

2:3. Hydrogen. - As a future energy carrier hydrogen seems to be rather ideal. It can be manufactured for example by using electricity via electrolysis with an efficiency of up to about $80 \%$. It can also be produced directly from sunlight by some green algae and cyanobacteria [8]. Although the production of this so-called photobiological hydrogen is still in an experimental phase with efficiencies of about $2 \%$, this development may become important in the future. Once produced, hydrogen can be used to generate electricity in a fuel cell with an efficiency of up to about $60 \%$ so far. The problem is to store hydrogen 
TABLE IV. - Properties of molecular hydrogen $\left(\mathrm{H}_{2}\right)$.

\begin{tabular}{ll}
\hline Heat of combustion $\left(\right.$ upper $\left.^{(a)}\right)$ & $12.8 \mathrm{MJ} / \mathrm{m}^{3}$ or $142 \mathrm{MJ} / \mathrm{kg}$ \\
Heat of combustion $\left(\right.$ lower $\left.^{(\text {a) }}\right)$ & $10.8 \mathrm{MJ} / \mathrm{m}^{3}$ or $120 \mathrm{MJ} / \mathrm{kg}$ \\
Density (at $0{ }^{\circ} \mathrm{C}, 1$ bar) & $0.090 \mathrm{~kg} / \mathrm{m}^{3}$ \\
Boiling point & $-253^{\circ} \mathrm{C}$ or $20.4 \mathrm{~K}$ \\
Density of liquid $\mathrm{H}_{2}$ & $71.0 \mathrm{~kg} / \mathrm{m}^{3}$ \\
Latent heat of vaporization & $449 \mathrm{~kJ} / \mathrm{kg}$ or $31.8 \mathrm{MJ} / \mathrm{m}^{3}$ liquid \\
\hline (a) The "upper" value includes the heat of condensation of the water vapour; the "lower" value does not.
\end{tabular}

in a form suitable for mobile use, since it is in a gaseous state at ambient temperatures. One should bear in mind that the density of gases at normal temperature and pressure is three orders of magnitude lower than for liquids.

The contemporary way to circumvent this storage problem is to compress the gas to pressures of, for example, 700 bar. In addition to requiring strong yet light and small containers, this has its limitations which are inherent to the hydrogen molecule. Since it is a light molecule having only two protons and two electrons, the attractive forces between molecules are small. The first consequence is that it has a very low boiling point: $20.4 \mathrm{~K}$ (see table IV).

The second consequence is that the repulsive forces are by far dominant at ambient temperature. This means that when compressing the gas, the pressure increases more than one would expect on the basis of the ideal-gas law. For example: at 700 bar the density is only $2 / 3$ of what one would naively expect. The third consequence is that, in the liquid phase, the attractive well is so shallow that it is relatively easy for the molecules to escape into the gaseous phase. In other words: the heat of vaporization is relatively small: it is only $31.8 \mathrm{~kJ} / \mathrm{L}$ ( or $0.90 \mathrm{~kJ} / \mathrm{mol}$ ), compared to $2400 \mathrm{~kJ} / \mathrm{L}$ (or $43 \mathrm{~kJ} / \mathrm{mol}$ ) for water. This low heat of vaporization is a drawback when storing hydrogen in the liquid phase: one needs very good thermal insulation if the boil-off is to be small.

This inevitable boil-off, combined with the fact that liquid hydrogen is more difficult to handle than ordinary fuels like gasoline, makes the liquid option not very suitable for cars. However, there may be a great future for the use of liquid hydrogen in aviation. There are several reasons for this. The first reason is that weight is an important issue in aviation. This is especially the case for long-haul flights, where the weight of the kerosene is comparable to the weight of the empty aircraft (see sect. 1`2). The weight of hydrogen per unit of energy is about a factor of 3 lower than for kerosene. The second reason is that the boil-off is much less of a problem, not only because the aircraft is airborne only for a limited amount of time, but also because the temperature difference between the liquid hydrogen and the outside air is much smaller at cruising altitude than it is at ambient temperature. The third reason is that refueling of aircraft is done by professionals only, which reduces the risk of accidents to a level which is comparable to the risk involved in handling kerosene. 
For the sake of completeness we also mention the option of storing hydrogen as a metal hydride. Some metals are capable of absorbing large amounts of hydrogen in atomic form, even to the extent that the amount of hydrogen per unit volume is larger than in the liquid phase. However, the disadvantage is that the "tank" is very heavy compared to the weight of the hydrogen inside. This is obvious because hydrogen is the lightest of the elements and metals tend to be heavy. An example of a metal-hydrogen compound ("metal hydride") is $\mathrm{LaNi}_{5} \mathrm{H}_{6}$, where hydrogen is stored in an alloy of lanthanum and nickel, both heavy metals. If we look up the masses of $\mathrm{La}$ and $\mathrm{Ni}$, we find that the mass ratio of hydrogen to metal is 6 to 432 . But the good news is that $6 \mathrm{~kg}$ of hydrogen enables us to travel 400 to $800 \mathrm{~km}$, depending on whether a combustion engine or a fuel cell is being used.

$\mathbf{2}$ 4. Metal fuels. - A recent development is the option of metal fuels [9]. This option can be completely $\mathrm{CO}_{2}$-emission free. The idea is to equip a car with a cartridge containing, for example, a few liters of porous micron-sized iron powder. When driving the car, the iron powder is dispersed in air and the powder is burned in a hot turbulent flame, converting the iron powder into micron-sized rust-powder. The combustion energy is then used to drive a Stirling engine. The burnt rust particles are stored in a separate compartment of the original cartridge and when returning home the (heavier) cartridge is brought back to the store, from where it is shipped to a central place where the rust is transferred back to micron-sized iron particles using some clean primary energy, like solar energy. A clear advantage is that the energy density of iron is rather high: about $60 \mathrm{MJ} / \mathrm{L}$. Note that metal fuels can be directly burned with air.

2.5. Solar power for transportation. - Designing an experimental racing vehicle powered by solar energy is relatively easy, as is demonstrated in the biannual World Solar Challenge race across Australia. An example of such a car is shown in fig. 1.

By contrast, it is quite a challenge to design a family car powered by solar energy. A group of students at the Eindhoven University of Technology in The Netherlands took up this challenge, and won the Cruiser Class of the World Solar Challenge 2013. They built a family car which can seat 4 persons and has a range of up to $1000 \mathrm{~km}$. The specifications of an updated version are shown in table $\mathrm{V}$.

This car, the Stella Lux, can be driven without the use of batteries under a clear sky at a speed of about $43 \mathrm{~km} / \mathrm{h}$. In practice also use Li-ion batteries having a capacity of $15 \mathrm{kWh}$ are used, which enable the car to have a range of $1000 \mathrm{~km}$ on a sunny day in The Netherlands, and about $650 \mathrm{~km}$ at night. The top speed is $125 \mathrm{~km} / \mathrm{h}$. But this comes at a price: the comfort is bound to be marginal (see fig. 2).

Can this concept be used also for aviation? After all, in the summer of 2016 a solarpowered airplane, the Solar Impulse 2, flew from New York City to Sevilla in Spain. It had $270 \mathrm{~m}^{2}$ of solar panels, delivering $66 \mathrm{~kW}$ peak. It used Li-ion batteries having a total energy of $164 \mathrm{kWh}$ and having a mass of $633 \mathrm{~kg}$. Granted, the speed was not particularly impressive, being $90 \mathrm{~km} / \mathrm{h}$ during day and $60 \mathrm{~km} / \mathrm{h}$ at night (to save energy), but it is only a start. Could this be scaled up to a commercial airliner comparable to, say, 


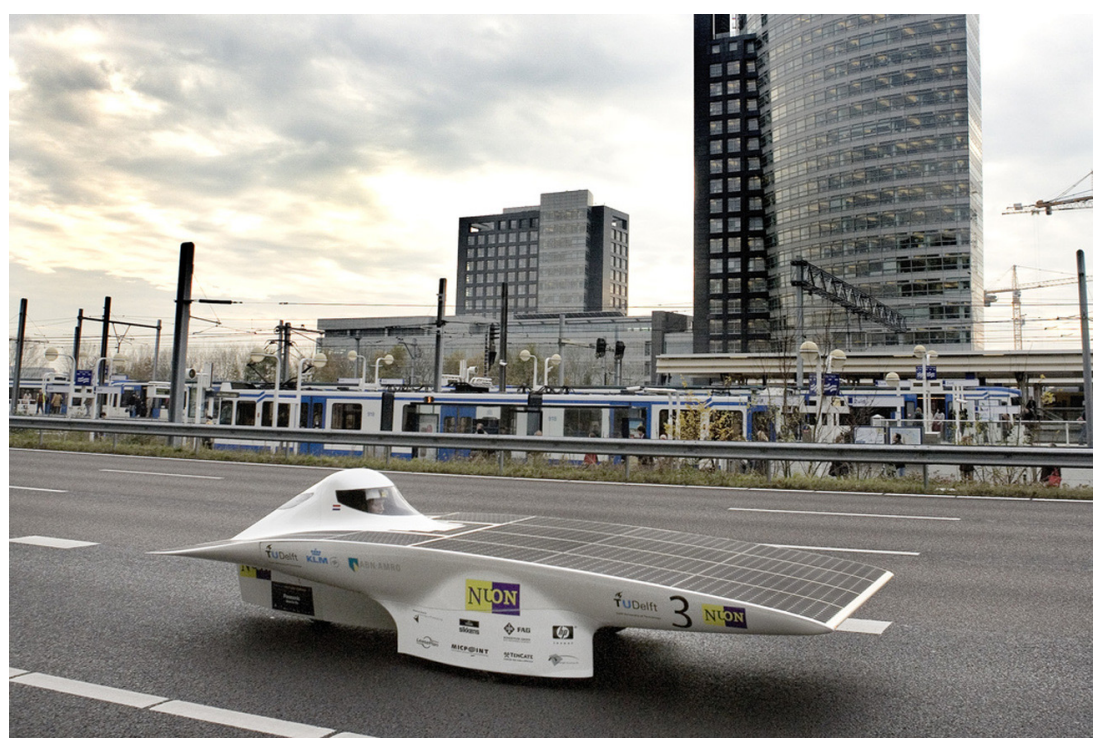

Fig. 1. - Solar racing car Nuna, winner of the World Solar Challenge in Australia. Using a $6 \mathrm{~m}^{2}$ area of solar cells having an efficiency over $26 \%$ and a $1.5 \mathrm{~kW}$ electric motor, its top speed was over $100 \mathrm{~km} / \mathrm{h}$. The mass was $190 \mathrm{~kg}$ and its rolling resistance only about 1/10 of that of a normal car.

a Boeing 747, with a reasonable speed? Alas, this is not the case, and it is easy to see why. The Boeing 747 has an engine power of about $110 \mathrm{MW}$ (which, by the way, is on the order of a small power plant!). Its wing area is $550 \mathrm{~m}^{2}$. Let us suppose we cover this area with solar panels having an efficiency of $20 \%$. We recall that the solar irradiance is almost exactly $1 \mathrm{~kW} / \mathrm{m}^{2}$, so that the maximum electrical power delivered by the total wing surface is $110 \mathrm{~kW}$. This happens to be three orders of magnitude smaller than the actual power mentioned above. So, unless revolutionary changes will take place in the plane concept, the idea of solar-powered passenger planes seems beyond hope.

TABLE V. - Technical specifications of the solar-powered family car "Stella Lux".

Number of seats

Height

Mass

Battery (Li-ion)

Solar array (monocrystalline $\mathrm{Si}, 23 \%$ efficiency)

Power at $100 \mathrm{~km} / \mathrm{h}$

Range on sunny day (Netherlands)

Range by night

Top speed/cruising speed

4

$1.12 \mathrm{~m}$

$375 \mathrm{~kg}$

$15 \mathrm{kWh}$

$5.8 \mathrm{~m}^{2}$

$\approx 1.5 \mathrm{~kW}$

$1000 \mathrm{~km}$

$\approx 650 \mathrm{~km}$

$125 / 70 \mathrm{~km} / \mathrm{h}$ 

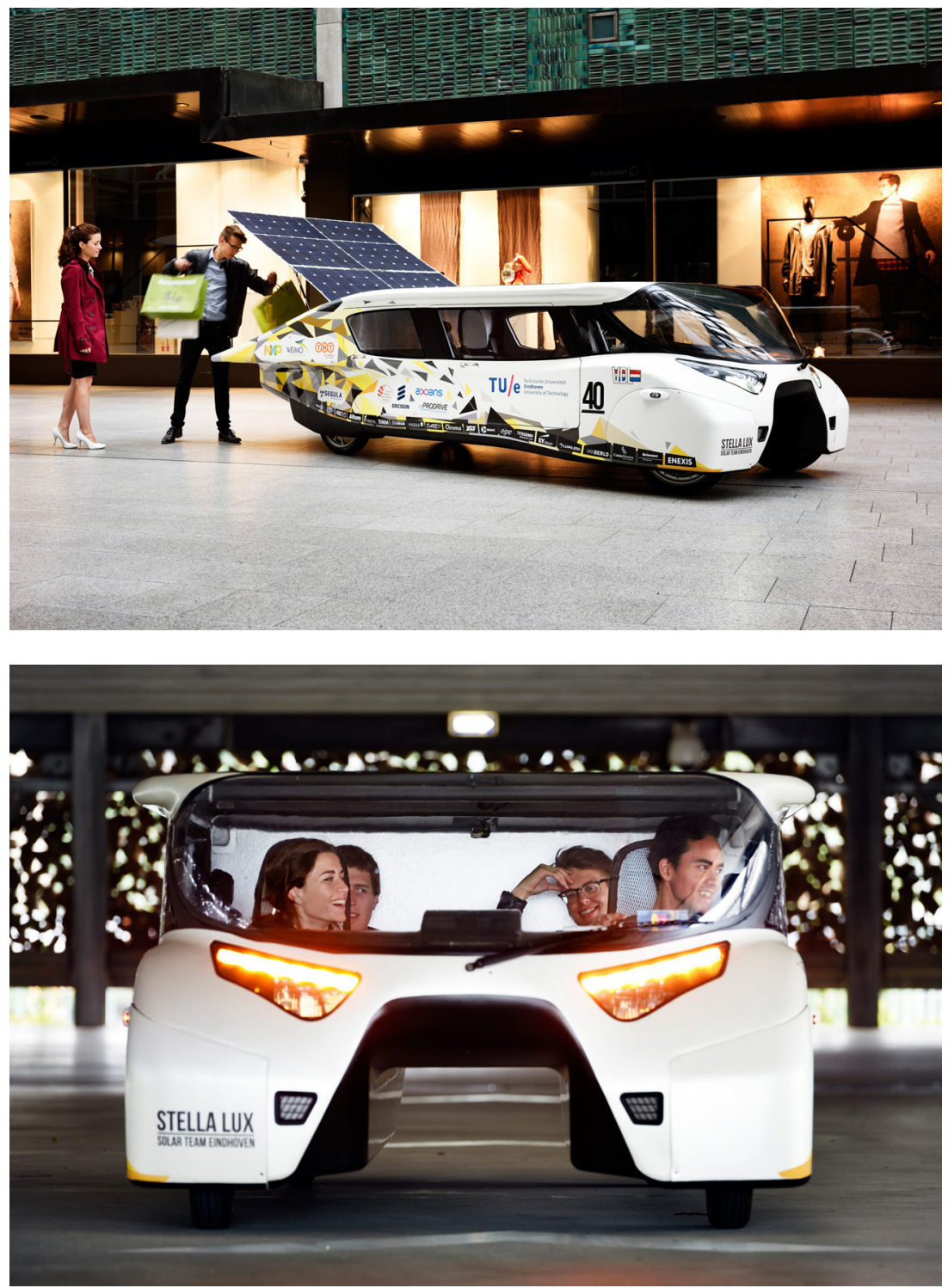

Fig. 2. - The solar-powered family car Stella Lux, built by a group of students at Eindhoven University of Technology, Eindhoven, The Netherlands (see table V). Courtesy: Solar Team Eindhoven.

\section{3. - The bicycle}

Of course the most sustainable means of transportation are those which are powered by human energy. Walking is relatively inefficient if it is compared to cycling. This 


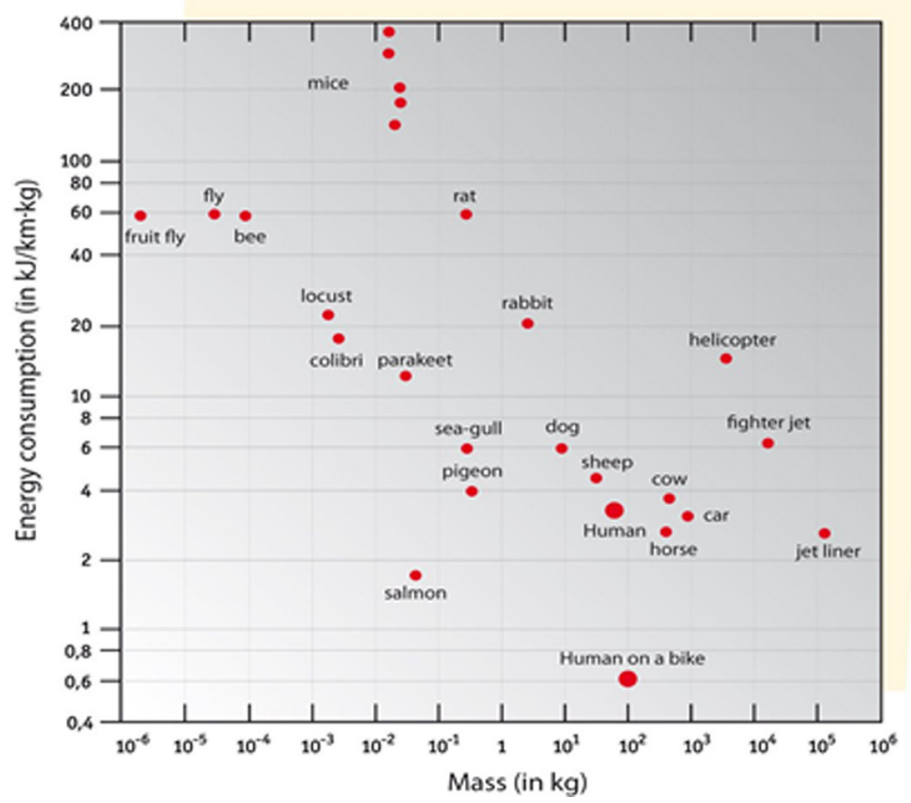

Fig. 3. - Energy use per $\mathrm{km}$ and per $\mathrm{kg}$ for various modes of transportation, arranged from low mass (left) to high mass (right).

can be readily understood, since cycling increases both the speed and the distance to be covered in a day by a factor of 4 to 5 with the same effort. This is also nicely illustrated in fig. 3 where various modes of transportation are compared. It is seen that a human being on a bicycle is the most efficient in terms of energy use per $\mathrm{km}$ and per $\mathrm{kg}$.

The number shown for a bicycle is slightly arbitrary, since it depends heavily on speed and on the sort of bicycle. To see this we turn to fig. 4, where the resistance for a cyclist is shown as a function of speed. It is seen that, for an ordinary city bike, the total resistance (and, consequently, the energy use per $\mathrm{km}$ ) goes up dramatically at higher speeds. This is because the air resistance (or drag) dominates above about $15 \mathrm{~km} / \mathrm{h}$. Consequently, the energy use per km also goes up dramatically at high speeds. The only way to reduce this is to decrease the aerodynamic drag, for example by assuming a streamlined, crouched position rather than sitting upright. This is pushed to the limit by Human Powered Vehicles (HPVs), in which the rider is often lying horizontally, and which have values of the drag coefficient $C_{\mathrm{d}}$ of around 0.1 instead of 1 , which is the value for a cyclist sitting upright on a city bike shown in fig. 4. This enables HPV riders to reach speeds far above $100 \mathrm{~km} / \mathrm{h}$, as demonstrated, for example, in 2015 by Todd Reichert, who rode his vehicle at a record speed of $139.45 \mathrm{~km} / \mathrm{h}$. Such high speeds are most often reached at elevated altitude (on Battle Mountain, Nevada in this case) to reduce drag by lowering the air density. 


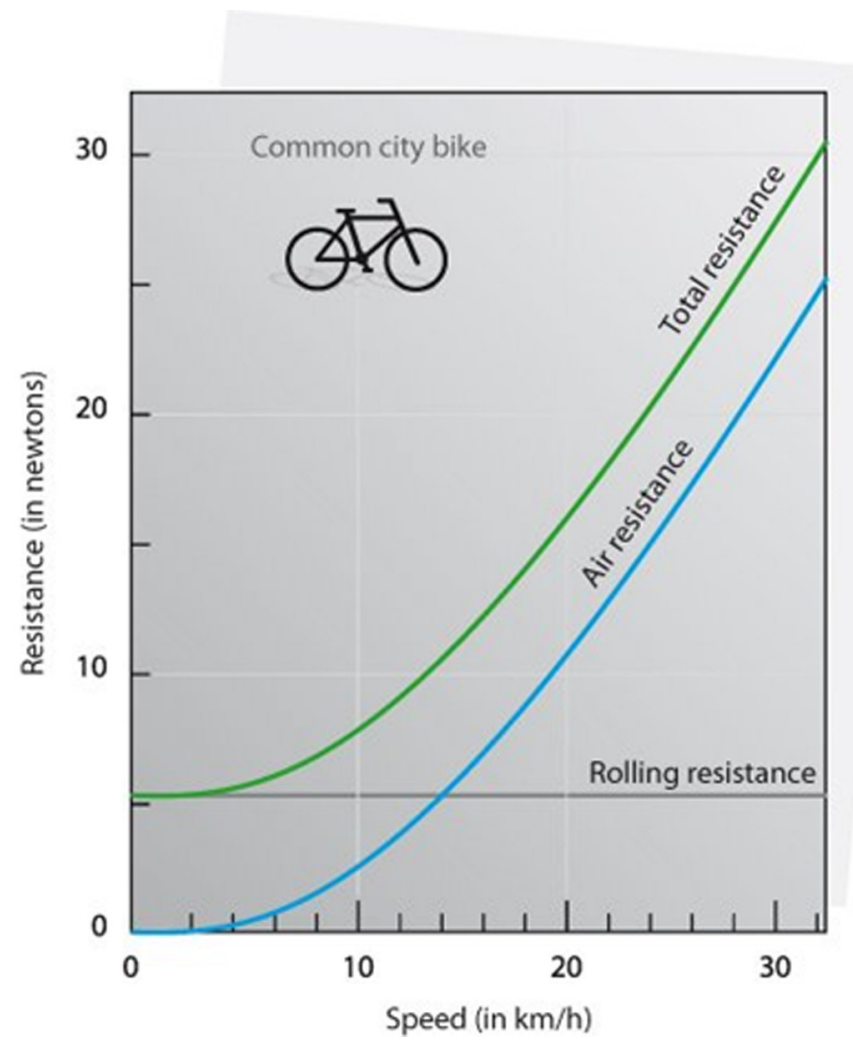

Fig. 4. - Rolling resistance and air resistance (or aerodynamic drag) for a city bike and a rider sitting upright. It is seen that drag is dominant above about $15 \mathrm{~km} / \mathrm{h}$.

\section{4. - Conclusion}

Achieving sustainable transport systems in the post-fossil-fuel era will pose a real challenge, because of the crucial role of liquid fuels in this sector. For cars and buses, batteries in combination with supercapacitors can provide a good alternative. Hydrogen in compressed form may also be an option, especially if used in combination with fuel cells. For aviation, some sort of liquid fuel with a high energy density seems to be indispensable in view of weight limitations. In this case liquid hydrogen may provide an excellent option for a number of reasons.

Direct use of solar power may be viable in some cases. Solar-powered vehicles are within reach, provided that customers are willing to accept a lower degree of comfort and speed. Solar-powered aviation, by contrast, seems beyond hope. And in view of the high efficiency of riding a bicycle, an excellent motto may be: cycle ... and recycle. 


\section{REFERENCES}

[1] National Academy of Sciences, Tires and Passenger Vehicle Fuel Economy (2006). Available at http://onlinepubs.trb.org/onlinepubs/sr/sr286.pdf; https://www.nap.edu/ catalog/11620/tires-and-passenger-vehicle-fuel-economy-informing-consumersimproving-performance.

[2] Hermans J., Energy Survival Guide (Leiden University Press, Leiden, The Netherlands) 2011.

[3] Cifarelli L. and Wagner F. (Editors), Energy: Basic Concepts and Forefront Ideas, in Lecture Notes Joint EPS-SIF International School on Energy (SIF, Bologna) 2015, p. 339.

[4] Lifecycle analysis by Transport $\& 3$ Environment, based on Globiom Study (2016), accessible by https://www.transportenvironment.org/sites/te/files/publications/2016\%2004 $\% 20$ Globiom\%20webinar.pdf.

[5] Ecofys, IIASA and E4tech, The land use change impact of biofuels consumed in the EU, Quantification of area and greenhouse gas impacts (2015), accessible by https://ec.europa.eu/energy/sites/ener/files/documents/Final\%20Report_GLOBIOM_ publication.pdf.

[6] Crabtree George, talk presented at the 69th Course of the International School of Solid State Physics: Materials for Energy and Sustainability V, Erice, Italy, 2016.

[7] Abruna H. D., Kiya Y. and Henderson J. C., Phys. Today, 61, issue No. 12 (2008) 43.

[8] De Groot H., private communication.

[9] Deen N., Bergthorson J., Shoshin Y. and Van Der Schaaf John, Energy Days, 27 October 2016, Eindhoven Energy Institute (Eindhoven University of Technology, The Netherlands) 2016. 